\title{
Patient gender as a factor associated with lymph node metastasis in T1 colorectal cancer: A systematic review and meta-analysis
}

\author{
KATSURO ICHIMASA ${ }^{1}$, SHIN-EI KUDO ${ }^{1}$, HIDEYUKI MIYACHI $^{1}$, YUTA KOUYAMA ${ }^{1}$, \\ FUMIO ISHIDA $^{1}$, TOSHIYUKI BABA ${ }^{1}$, ATSUSHI KATAGIRI ${ }^{1}$, KUNIHIKO WAKAMURA ${ }^{1}$, \\ TAKEMASA HAYASHI $^{1}$, TOMOKAZU HISAYUKI ${ }^{1}$, TOYOKI KUDO ${ }^{1}$, MASASHI MISAWA ${ }^{1}$, \\ YUICHI MORI $^{1}$, SHINGO MATSUDAIRA ${ }^{1}$, YUI KIMURA ${ }^{1}$ and YUKI KATAOKA $^{2}$ \\ ${ }^{1}$ Digestive Disease Center, Showa University Northern Yokohama Hospital, Yokohama, Kanagawa 224-8503; \\ ${ }^{2}$ Hospital Care Research Unit, Hyogo Prefectural Amagasaki General Medical Center, Amagasaki, Hyogo 660-8550, Japan
}

Received June 10, 2016; Accepted January 11, 2017

DOI: $10.3892 / \mathrm{mco} .2017 .1172$

\begin{abstract}
Approximately 10\% of patients with T1 colorectal cancer have lymph node metastases (LNM), requiring node dissection along with surgical resection. Patient gender was recently reported to affect the occurrence of LNM. The aim of the present study was to assess whether patient gender was predictive of LNM in T1 colorectal cancer. Public databases, including PubMed, EMBASE and the Cochrane Central Register of Controlled Trials were searched, using key terms related to 'T1 colorectal cancer' and 'lymph node'. All relevant studies reporting the adjusted odds ratio or risk ratio of LNM in relation to patient gender were included. The quality of the studies was classified according to the Quality in Prognostic Studies tool. A random-effects model was used and the quality of the evidence was evaluated using the Grading of Recommendations Assessment, Development and Evaluation approach. The initial database search identified 2,492 publications; of those, 36 studies reported unadjusted results. Of the 36 studies, 4 reported adjusted results and fulfilled the inclusion criteria for this meta-analysis: 3 studies were graded as having a moderate risk of bias, and 1 had a low risk of bias. The present meta-analysis demonstrated that female gender was associated with increased risk of LNM (risk ratio $=2.45$, 95\% confidence interval: 1.03-3.88). The $\mathrm{I}^{2}$ statistic was 0.901 , classified as very low (+OOO) and was downgraded by the risk of bias, inconsistency and publication bias. In conclusion, female gender was found to be correlated with LNM in patients with $\mathrm{T} 1$ colorectal cancer.
\end{abstract}

Correspondence to: Dr Shin-Ei Kudo, Digestive Disease Center, Showa University Northern Yokohama Hospital, 35-1 Chigasaki Chuo, Tsuzuki-ku, Yokohama, Kanagawa 224-8503, Japan

E-mail:kudos@med.showa-u.ac.jp

Key words: colorectal cancer, female, lymph node metastasis, gender, $\mathrm{T} 1$ cancer

\section{Introduction}

Colorectal cancer is one of the most common types of cancer worldwide. Due to the advances in endoscopic treatment, particularly endoscopic submucosal dissection, several T1 colorectal cancers are resected endoscopically with negative margins (1-3). Lymph node metastasis (LNM) occurs in $\sim 10 \%$ of patients with $\mathrm{T} 1$ colorectal cancer, with these patients requiring surgical resection with lymph node dissection (4-7). Therefore, determining risk factors associated with LNM in patients with $\mathrm{T} 1$ colorectal cancer is crucial.

A number of studies have assessed factors predictive of LNM in patients with T1 colorectal cancer. Previously identified risk factors for LNM include lymphovascular invasion, histological grade, tumor budding and degree of submucosal invasion (8-10). These factors are included in various diagnostic and treatment guidelines, including those of the National Comprehensive Cancer Network, the European Society for Medical Oncology and the Japanese Society for Cancer of the Colon and Rectum (8-10). However, the majority of the studies identifying these guidelines were retrospective in design and included small numbers of patients. In addition, these analyses were limited to pathological factors. The indications for additional surgery plus lymph node dissection following endoscopic resection remain unclear.

A recent retrospective, single-center study, which included a large number of patients, reported that female gender was associated with LNM in patients with T1 colorectal cancer (4). Other studies also reported higher rates of LNM in female compared with male patients, although these differences were not statistically significant $(11,12)$. Several systematic reviews and meta-analyses have investigated risk factors for LNM; however, none has focused on patient gender as a predictive factor for LNM to date (13-17). The aim of the present systematic review and meta-analysis was to assess whether the gender of patients with $\mathrm{T} 1$ colorectal cancer is predictive of LNM.

\section{Materials and methods}

Search strategy and selection criteria. This systematic review and meta-analysis was performed according to the Preferred 
Reporting Items for Systematic Reviews and Meta-Analyses (PRISMA) statement, was conducted in accordance with the Cochrane Handbook $(18,19)$ and was pre-registered (CRD42015024588). MEDLINE, EMBASE and the Cochrane Central Register of Controlled Trials were searched from the earliest date of indexing through July 11, 2015. The search terms included 'T1', 'early', 'colorectal', 'colonic', 'rectal', 'adenocarcinoma', 'neoplasm', 'lymph node', 'N1' and 'N2' in various combinations. Additional searches were performed by manual cross-referencing. Only studies published in English were included. The meta-analysis was restricted to studies reporting the adjusted odds ratio $(\mathrm{aOR})$ or risk ratio $(\mathrm{RR})$ of dissection-diagnosed LNM in relation to gender in patients with T1 colorectal cancer. Patients with familial adenomatous polyposis, Lynch syndrome and ulcerative colitis were excluded, as were patients who underwent only endoscopic treatment or transanal endoscopic microsurgery.

Data extraction. Two authors (K.I. and Y.K.) independently reviewed the abstracts and titles identified by the searches. All studies rated as possible candidates by either of these two reviewers were included in the preliminary list, and their full texts were retrieved. The two authors independently reviewed the full texts to determine whether the studies met the review criteria. Disagreements were resolved by discussion, or if necessary by a third reviewer (Y.K.). Information extracted from studies deemed to have met the review criteria included name of first author, year of publication, country, study design, number of patients, study inclusion and exclusion criteria, study quality, demographic data and outcome events.

Risk of bias. Two authors (K.I. and Y.K.) independently assessed the risk of bias using the Quality in Prognostic Studies (QUIPS) tool (20). Each domain was rated as being at low, high or unclear risk of bias, based on whether the study sample adequately represented the population of interest; whether the participants not lost to follow-up adequately represented the study sample; whether prognostic factors and outcomes of interest were measured similarly for all participants; and whether there were other sources of bias. Disagreements between reviewers were resolved by discussion.

Statistical analysis. Data were analyzed by a single investigator (Y.K.). All studies included in the meta-analysis reported the frequency of LNM in men and women, either in the text or in the tables. Data were synthesized using Stata software, version 13.0 (Stata Corp., College Station, TX, USA). A meta-analysis was performed to summarize the prognostic effects of gender, with results reported as RR and $95 \%$ confidence interval (CI). A random-effects model was used. The quality of evidence was evaluated using the Grading of Recommendations Assessment, Development and Evaluation (GRADE) approach (21). Heterogeneity was assessed by visual inspection of the forest plots. $\mathrm{I}^{2}$ statistics were calculated and analyzed based on the recommendations of the Cochrane Handbook, in which $\mathrm{I}^{2}$ values of 0-40, 30-60, 50-90 and $75-100 \%$ represent little, moderate, substantial and considerable heterogeneity, respectively (19). A sensitivity analysis was conducted to pool all 36 studies reporting unadjusted relative risk of gender. A subgroup analysis could not be conducted due to data insufficiency. P-values $<0.05$ were considered to indicate statistically significant differences.

\section{Results}

Study selection and inclusion. The initial database search identified 2,492 publications. Following removal of duplicates, 2,489 unique publications were identified, 1,419 on PubMed, 1,889 on EMBASE and 162 on the Cochrane Library. Three additional publications were identified through other sources or from the references lists of the included publications. After screening the titles and abstracts, 441 full-text articles were assessed for eligibility (first review). Of those, 36 studies reported unadjusted results and were included for systematic review (second review). Of the 36 studies, 4 (4,22-24) reported adjusted results and fulfilled the predetermined inclusion criteria for the meta-analysis (Fig. 1).

Characteristics of included studies. The 4 studies included in this meta-analysis were retrospective in design and involved 1,329 patients with $\mathrm{T} 1$ colorectal cancer. Of the 4 studies, 3 were single-center and 1 was a multicenter study. As regards bias, 3 studies were graded as having a moderate risk of bias and 1 as having a low risk of bias. The median number of patients per study was 332 (range, 142-653). Of the 1,329 included patients, $864(65.0 \%)$ were male and $465(35.0 \%)$ were female; $558(42.0 \%)$ had rectal carcinomas and $771(58.0 \%)$ had colon carcinomas. The characteristics of the 4 included studies are presented in Table I.

Of the 1,329 patients, $113(8.5 \%$; 95\% CI: 7.1-10.1) were positive for LNM, with the number per study ranging from 6.3 to 9.9\%. The incidence of LNM was 6.4\% (55/864, 95\% CI: 4.8-8.2) in male and $12.5 \%(58 / 465,95 \%$ CI: $9.6-15.8)$ in female patients.

Quality of evidence. Publication bias could not be evaluated using funnel plots or Egger's regression test. Only 4 of 36 studies reported adjusted outcomes, suggesting a selective outcome reporting bias (25). The risk of bias was serious, as the number of studies with a low risk of bias was limited. The $\mathrm{I}^{2}$ statistic was 0.901 , classified as very low (+OOO), and was downgraded by the risk of bias, inconsistency and publication bias (Table II).

Patient gender as a predictive factor for LNM. Of the 4 studies, 3 reported a higher rate of LNM in female compared with male patients with $\mathrm{T} 1$ colorectal cancer (10.8 vs. $4.6 \%, 15.7$ vs. $4.2 \%$ and 12.7 vs. $7.1 \%$, respectively), whereas 1 study reported a lower rate of LNM in female patients (8.3 vs. 10.6\%) (4,22-24). Of the 4 studies, $2(4,23)$ reported that female gender was an independent risk factor for LNM in patients with T1 colorectal cancer $(\mathrm{OR}=5.68$ and 2.22, respectively), whereas the remaining 2 studies $(22,24)$ reported no significant difference between male and female patients on the univariate as well as the multivariate analyses. The result of the meta-analysis for multivariate risk ratio is shown in Fig. 2. The weights were from the random-effects analysis. The meta-analysis demonstrated that female gender was associated with LNM in patients with T1 colorectal cancer ( $\mathrm{RR}=2.45,95 \% \mathrm{CI}$ : 1.03-3.88).

Sensitivity analysis. The pooled sensitivity analysis of the 36 studies revealed that female gender was associated with LNM 

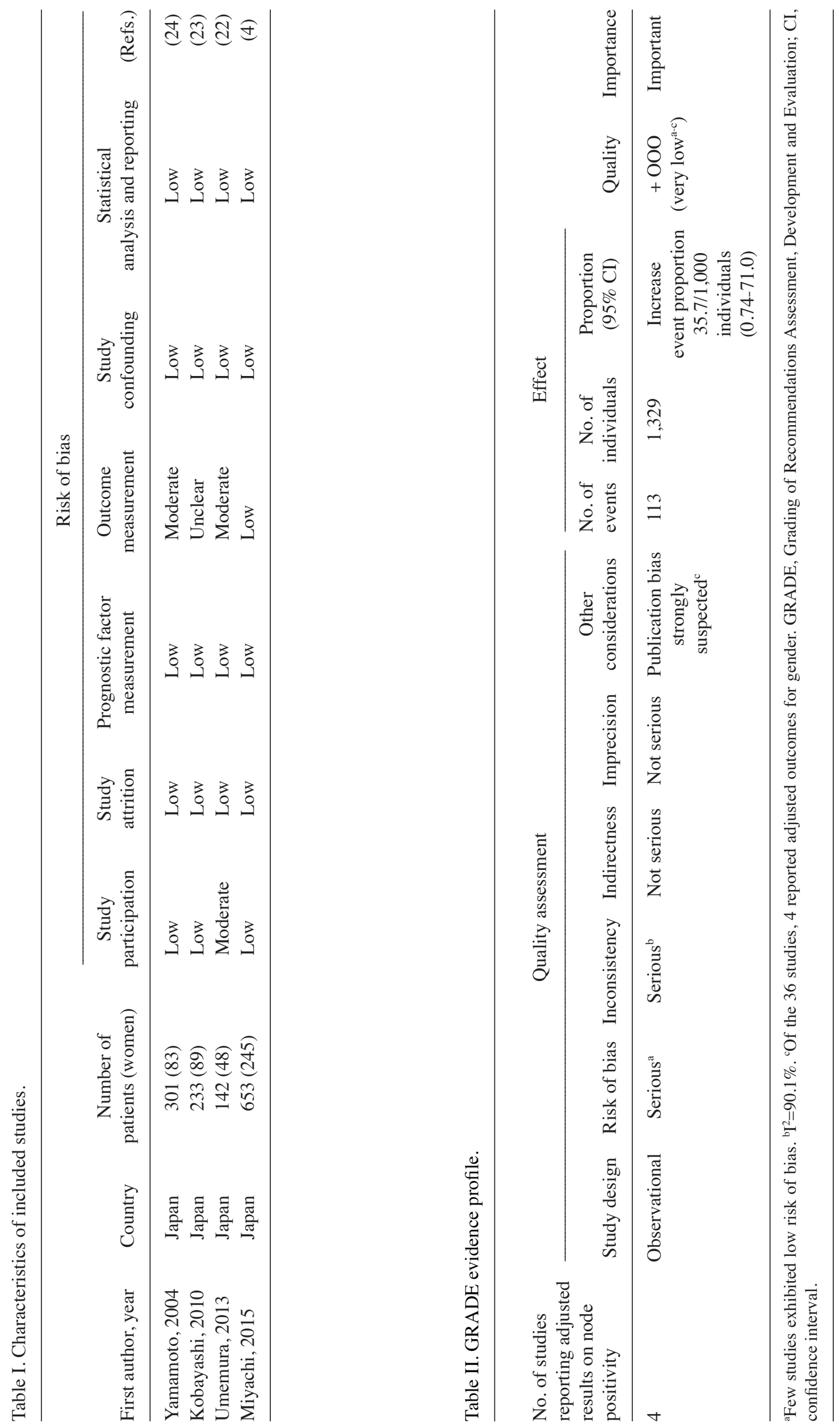


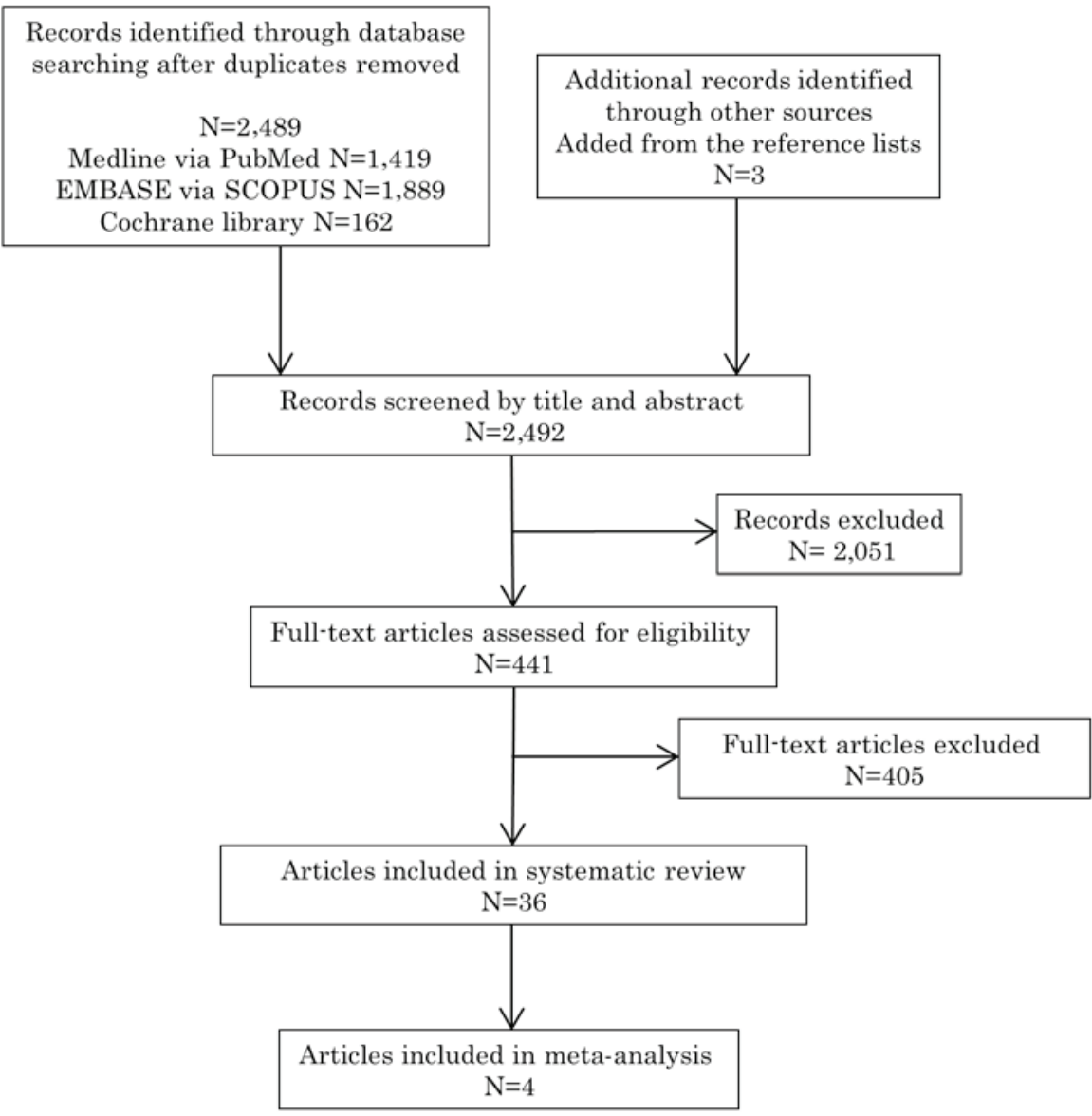

Figure 1. Flow diagram of the study selection process.

\begin{tabular}{|c|c|c|}
\hline Author & $\mathrm{RR}(95 \% \mathrm{Cl})$ & Weight \\
\hline Yamamoto (2004) & $2.07(1.03,3.10)$ & 24.55 \\
\hline Kobayashi (2010) & $4.77(3.78,5.76)$ & 24.86 \\
\hline Umemura (2013) & $0.88(-0.34,2.10)$ & 23.34 \\
\hline Miyachi (2015) & $2.04(1.53,2.55)$ & 27.24 \\
\hline Overall $\left(I^{2}=90.1 \%, P=0.000\right)$ & $2.45(1.03,3.88)$ & 100.00 \\
\hline NOTE: Weights are from random-effects analysis & & \\
\hline
\end{tabular}

Figure 2. Meta-analysis for multivariate risk ratios (RRs). CI, confidence interval.

(RR=1.33, 95\% CI: 1.17-1.51; Fig. 3), which was consistent with the main results $(4-6,11,12,22-24,26-49)$.

\section{Discussion}

In the present study, the association between patient gender and LNM in patients with T1 colorectal cancer was systematically reviewed. Our meta-analysis revealed that female gender was associated with LNM in T1 colorectal cancer. To the best of our knowledge, this is the first such analysis showing that patient gender is predictive of LNM in patients with T1 colorectal cancer.

Overall, $10 \%$ of patients with $\mathrm{T} 1$ colorectal cancers have LNM, thereby requiring more invasive surgery along with lymph node dissection (4-7). Operative treatments are relatively invasive and costly, making local excision an attractive 


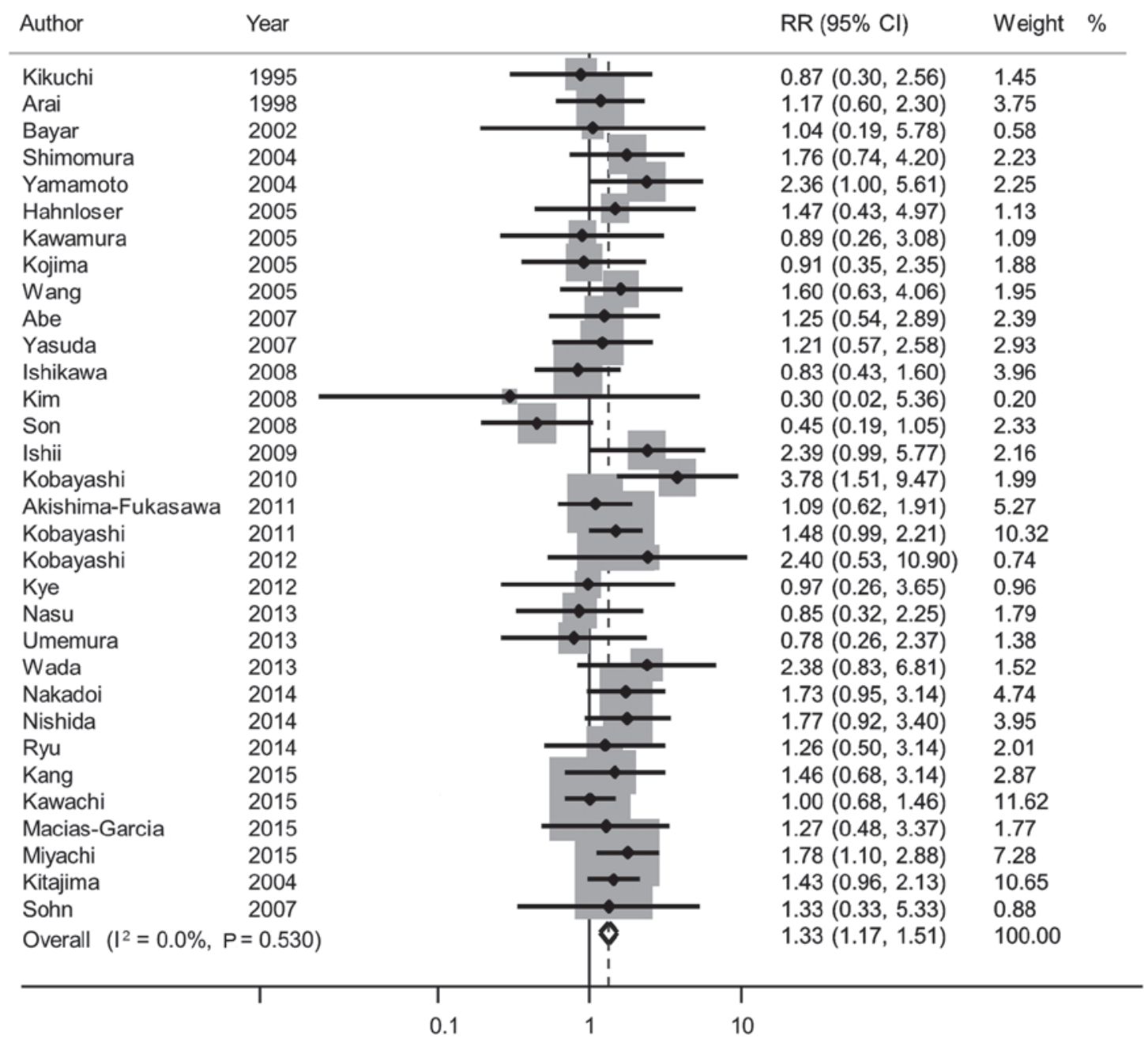

Figure 3. Sensitivity analysis. RR, risk ratio; CI, confidence interval.

treatment option. However, local excision is oncologically safe only in the absence of LNM. As LNM is difficult to assess preoperatively, the decision to perform radical surgery following endoscopic resection is based on the results of clinicopathological analysis. Several previous systematic reviews of small, retrospective studies have identified reliable pathological factors associated with the risk of LNM in T1 colorectal cancer (13-17). These meta-analyses reported that depth of submucosal invasion $>1,000 \mu \mathrm{m}$, lymphovascular invasion, poorly differentiated tumors and tumor budding were all risk factors for LNM. The diagnosis of pathological factors may differ among observers $(38,50)$. Moreover, pathological diagnoses may depend on the immunohistochemical assay used, such as D2-40, Victoria Blue and CAM 5.2. For example, lymphatic invasion is more accurately diagnosed using an anti-human podoplanin antibody rather than by hematoxylin and eosin staining (51-53). By contrast, our meta-analysis was the first to demonstrate that patient gender as a new clinical risk factor was predictive of LNM. Moreover, in contrast to the other meta-analyses, ours assessed the risk of bias of each study using the QUIPS tool and evaluated the quality of evidence using the GRADE approach.

A recent study of 653 patients with $\mathrm{T} 1$ colorectal cancer demonstrated that female gender was an independent risk factor for LNM (4). Stratification of patients according to the status of the muscularis mucosae (whether the muscle fibers were maintained or fragmented/disappeared), pathological factors and patient gender provides more appropriate indications for additional surgery along with lymph node dissection in this patient population, and may help reduce the incidence of unnecessary surgery. Several other studies also reported that the rate of LNM was higher in female compared with male patients $(5,11)$, and that female gender was an independent risk factor for LNM in patients with T1 lower rectal cancer (23).

Although the mechanism underlying the higher rate of LNM in women with $\mathrm{T} 1$ colorectal cancer has not been fully elucidated, epidemiological studies have reported a potential association between gender hormones and colorectal cancer (54-56). Some studies indicate a role for estrogen in the protection against colorectal cancer (55-58). The effects of estrogen are mediated by estrogen receptors (ERs), namely ER $\alpha$ and $\operatorname{ER} \beta(59,60)$. ER $\beta$ expression was found to be significantly reduced in adenomatous tissues with high levels of dysplasia as well as in carcinomatous tissues compared with normal mucosa (61). In addition, the degree of ER $\beta$ expression loss appears to be correlated with more advanced stage and higher tumor grade $(62,63)$. The degree of reduction in ER $\beta$ level may also be correlated with LNM. Nussler et al reported that ER $\beta$ levels were significantly reduced in colorectal cancer in both men and women compared with normal colonic mucosa, and this reduction in ER $\beta$ level 
was different by gender (64). Other studies were unable to detect such gender differences $(62,65)$. However, the samples of all those studies were very limited and investigation using larger sample sizes would be required to demonstrate the difference in ER $\beta$ levels by gender. Furthermore, not only a reduction of the ER $\beta$ levels, but more importantly, a change in the $\operatorname{ER} \alpha: \operatorname{ER} \beta$ ratio, may determine the susceptibility of a given tissue to carcinogenesis $(66,67)$. This is only one plausible reason and there may be other possible explanations for the association between LNM and gender in T1 colorectal cancer; therefore, further investigation is required.

This meta-analysis had several limitations. The main limitation was the lack of randomized controlled trials, as confounding factors may be more effectively removed from a randomized trial rather than from an observational study. As the patients in these studies were not randomized by gender, our analysis may have been sensitive to confounding variables. Therefore, only studies with adjusted results were included. Second, only 4 of the 36 studies reported adjusted results. Thus, a selective outcome reporting bias may have led to the gender-related difference in LNM rate. Our sensitivity analysis included all 36 studies, with the results not differing markedly. Third, all the studies in this meta-analysis originated in Japan, which may have affected our results. Only 3 of the 36 studies were from western countries, none of which reported adjusted results, and were thus excluded from the current criteria $(28,30,48)$. In fact, these 3 studies showed a tendency of higher LNM rate in female rather than in male patients, but the difference was not significant due to insufficient number $(<100)$ of study subjects. The association between female gender and LNM may differ by race. However, such a meta-analysis including western populations cannot be conducted at present; thus, this risk factor requires larger-scale validation in western countries. In our meta-analysis, 1 of the 4 included studies reported a higher LNM rate in male rather than female patients, although the difference was not statistically significant. There was little clinical heterogeneity. Thus, this difference may be due to chance by small sample size.

In conclusion, the gender of patients with $\mathrm{T} 1$ colorectal cancer was found to be predictive of LNM. This finding may help select patients who may be spared radical resection, thereby preventing unnecessary surgery without compromising oncological safety. Further prospective randomized studies with larger patient populations are required to confirm this result.

\section{Acknowledgements}

The authors would like to thank Yoko Tanaka for assisting with the English composition of the manuscript, and all members of the Digestive Disease Center and the Department of Pathology of Showa University Northern Yokohama Hospital for their excellent assistance.

\section{References}

1. Lee EJ, Lee JB, Lee SH and Youk EG: Endoscopic treatment of large colorectal tumors: Comparison of endoscopic mucosal resection, endoscopic mucosal resection-precutting and endoscopic submucosal dissection. Surg Endosc 26: 2220-2230, 2012.
2. Tanaka S, Oka S, Kaneko I, Hirata M, Mouri R, Kanao H, Yoshida S and Chayama K: Endoscopic submucosal dissection for colorectal neoplasia: Possibility of standardization. Gastrointest Endosc 66: 100-107, 2007.

3. Kobayashi N, Saito Y, Uraoka T, Matsuda T, Suzuki H and Fujii T: Treatment strategy for laterally spreading tumors in Japan: Before and after the introduction of endoscopic submucosal dissection. J Gastroenterol Hepatol 24: 1387-1392, 2009.

4. Miyachi H, Kudo SE, Ichimasa K, Hisayuki T, Oikawa H, Matsudaira S, Kouyama Y, Kimura YJ, Misawa M, Mori Y, et al: Management of T1 colorectal cancers after endoscopic treatment based on the risk stratification of lymph node metastasis. J Gastroenterol Hepatol 31: 1126-1132, 2016.

5. Kobayashi H, Mochizuki H, Morita T, Kotake K, Teramoto T, Kameoka S, Saito Y, Takahashi K, Hase K, Oya M, et al: Characteristics of recurrence after curative resection for $\mathrm{T} 1$ colorectal cancer: Japanese multicenter study. J Gastroenterol 46: 203-211, 2011.

6. Son HJ, Song SY, Lee WY, Yang SS, Park SH, Yang MH, Yoon SH and Chun HK: Characteristics of early colorectal carcinoma with lymph node metastatic disease. Hepatogastroenterology 55: 1293-1297, 2008

7. Hackelsberger A, Fruhmorgen P, Weiler H, Heller T, Seeliger H and Junghanns K: Endoscopic polypectomy and management of colorectal adenomas with invasive carcinoma. Endoscopy 27: 153-158, 1995.

8. Benson AB III, Bekaii-Saab T, Chan E, Chen YJ, Choti MA, Cooper HS, Engstrom PF, Enzinger PC, Fakih MG, Fenton MJ, et al: Localized colon cancer, version 3.2013: Featured updates to the NCCN Guidelines. J Natl Compr Canc Netw 11: 519-528, 2013.

9. Labianca R, Nordlinger B, Beretta GD, Mosconi S, Mandalà M, Cervantes A and Arnold D; ESMO Guidelines Working Group: Early colon cancer: ESMO clinical practice guidelines for diagnosis, treatment and follow-up. Ann Oncol 24 (Suppl 6): vi64-vi72, 2013.

10. Watanabe T, Itabashi M, Shimada Y, Tanaka S, Ito Y, Ajioka Y, Hamaguchi T, Hyodo I, Igarashi M, Ishida H, et al: Japanese Society for Cancer of the Colon and Rectum (JSCCR) Guidelines 2014 for treatment of colorectal cancer. Int J Clin Oncol 20: 207-239, 2015.

11. Nakadoi K, Oka S, Tanaka S, Hayashi N, Terasaki M, Arihiro K, Shimamoto F and Chayama K: Condition of muscularis mucosae is a risk factor for lymph node metastasis in T1 colorectal carcinoma. Surg Endosc 28: 1269-1276, 2014.

12. Kitajima K, Fujimori T, Fujii S, Takeda J, Ohkura Y, Kawamata H, Kumamoto T, Ishiguro S, Kato Y, Shimoda T, et al: Correlations between lymph node metastasis and depth of submucosal invasion in submucosal invasive colorectal carcinoma: A Japanese collaborative study. J Gastroenterol 39: 534-543, 2004.

13. Wada H, Shiozawa M, Katayama K, Okamoto N, Miyagi Y, Rino Y, Masuda M and Akaike M: Systematic review and meta-analysis of histopathological predictive factors for lymph node metastasis in T1 colorectal cancer. J Gastroenterol 50: 727-734, 2015.

14. Choi JY, Jung SA, Shim KN, Cho WY, Keum B, Byeon JS, Huh KC, Jang BI, Chang DK, Jung HY, et al: Meta-analysis of predictive clinicopathologic factors for lymph node metastasis in patients with early colorectal carcinoma. J Korean Med Sci 30: 398-406, 2015.

15. Beaton C, Twine CP, Williams GL and Radcliffe AG: Systematic review and meta-analysis of histopathological factors influencing the risk of lymph node metastasis in early colorectal cancer. Colorectal Dis 15: 788-797, 2013

16. Bosch SL, Teerenstra S, de Wilt JH, Cunningham $\mathrm{C}$ and Nagtegaal ID: Predicting lymph node metastasis in pT1 colorectal cancer: A systematic review of risk factors providing rationale for therapy decisions. Endoscopy 45: 827-834, 2013.

17. Mou S, Soetikno R, Shimoda T, Rouse R and Kaltenbach T: Pathologic predictive factors for lymph node metastasis in submucosal invasive (T1) colorectal cancer: A systematic review and meta-analysis. Surg Endosc 27: 2692-2703, 2013.

18. Moher D, Liberati A, Tetzlaff J and Altman DG; PRISMA Group: Preferred reporting items for systematic reviews and meta-analyses: The PRISMA statement. PLoS Med 6: e1000097, 2009.

19. Higgins J and Green S: Cochrane Handbook for Systematic Reviews of Interventions Version 5.1.0 [updated March 2011]. 2008. The Cochrane Collaboration, 2011. 
20. Hayden JA, van der Windt DA, Cartwright JL, Côté P and Bombardier C: Assessing bias in studies of prognostic factors. Ann Intern Med 158: 280-286, 2013.

21. Iorio A, Spencer FA, Falavigna M, Alba C, Lang E, Burnand B, McGinn T, Hayden J, Williams K, Shea B, et al: Use of GRADE for assessment of evidence about prognosis: Rating confidence in estimates of event rates in broad categories of patients. BMJ 350: h870, 2015.

22. Umemura K, Takagi S, Shimada T, Masuda T, Shiga H, Takahashi S, Takahashi S, Kinouchi Y, Shibuya D and Shimosegawa T: Prognostic and diagnostic significance of tumor budding associated with $\beta$-catenin expression in submucosal invasive colorectal carcinoma. Tohoku J Exp Med 229: 53-59, 2013.

23. Kobayashi H, Mochizuki H, Kato T, Mori T, Kameoka S, Shirouzu K, Saito Y, Watanabe M, Morita T, Hida J, et al: Is total mesorectal excision always necessary for T1-T2 lower rectal cancer? Ann Surg Oncol 17: 973-980, 2010.

24. Yamamoto S, Watanabe M, Hasegawa H, Baba H, Yoshinare K, Shiraishi J and Kitajima M: The risk of lymph node metastasis in T1 colorectal carcinoma. Hepatogastroenterology 51: 998-1000, 2004.

25. Chan AW, Hróbjartsson A, Haahr MT, Gøtzsche PC and Altman DG: Empirical evidence for selective reporting of outcomes in randomized trials: Comparison of protocols to published articles. J Am Med Assoc 291: 2457-2465, 2004.

26. Kikuchi R, Takano M, Takagi K, Fujimoto N, Nozaki R, Fujiyoshi T and Uchida Y: Management of early invasive colorectal cancer. Risk of recurrence and clinical guidelines. Dis Colon Rectum 38: 1286-1295, 1995.

27. Arai T, Akiyama Y, Yamamura A, Hosoi T, Shibata T, Saitoh K, Okabe S and Yuasa Y: Allelotype analysis of early colorecta cancers with lymph node metastasis. Int J Cancer 79: 418-423, 1998.

28. Bayar S, Saxena R, Emir B and Salem RR: Venous invasion may predict lymph node metastasis in early rectal cancer. Eur J Surg Oncol 28: 413-417, 2002

29. Shimomura $T$, Ishiguro $\mathrm{S}$, Konishi $\mathrm{H}$, Wakabayashi $\mathrm{N}$, Mitsufuji S, Kasugai T, Manou M and Kodama T: New indication for endoscopic treatment of colorectal carcinoma with submucosal invasion. J Gastroenterol Hepatol 19: 48-55, 2004.

30. Hahnloser D, Wolff BG, Larson DW, Ping J and Nivatvongs S: Immediate radical resection after local excision of rectal cancer: An oncologic compromise? Dis Colon Rectum 48: 429-437, 2005

31. Kawamura YJ, Sakuragi M, Togashi K, Okada M, Nagai H and Konishi F: Distribution of lymph node metastasis in T1 sigmoid colon carcinoma: Should we ligate the inferior mesenteric artery? Scand J Gastroenterol 40: 858-861, 2005.

32. Kojima M, Shiokawa A, Ohike N, Ohta Y, Kato H, Iwaku K, Hayasi R and Morohoshi T: Clinical significance of nuclear morphometry at the invasive front of $\mathrm{T} 1$ colorectal cancer and relation to expression of VEGF-A and VEGF-C. Oncology 68 230-238, 2005

33. Wang HS, Liang WY, Lin TC, Chen WS, Jiang JK, Yang SH, Chang SC and Lin JK: Curative resection of T1 colorectal carcinoma: Risk of lymph node metastasis and long-term prognosis. Dis Colon Rectum 48: 1182-1192, 2005.

34. Abe A, Fukui H, Fujii S, Fujita M, Mukawa K, Ichikawa K, Tomita S, Ono Y, Imai Y, Imura J, et al: Involvement of cyclooxygenase-2 and vascular endothelial growth factor in vascularization and lymph node metastasis of colorectal cancers with submucosal invasion. J Gastroenterol Hepatol 22: 1071-1077, 2007.

35. Yasuda K, Inomata M, Shiromizu A, Shiraishi N, Higashi $H$ and Kitano S: Risk factors for occult lymph node metastasis of colorectal cancer invading the submucosa and indications for endoscopic mucosal resection. Dis Colon Rectum 50: 1370-1376, 2007.

36. Ishikawa Y, Akishima-Fukasawa Y, Ito K, Akasaka Y, Yokoo T and Ishii T; Toho Study Group for Cancer Biological Behavior: Histopathologic determinants of regional lymph node metastasis in early colorectal cancer. Cancer 112: 924-933, 2008.

37. Kim JH, Cheon JH, Kim TI, Baik SH, Kim NK, Kim H and Kim WH: Effectiveness of radical surgery after incomplete endoscopic mucosal resection for early colorectal cancers: A clinical study investigating risk factors of residual cancer. Dig Dis Sci 53: 2941-2946, 2008.

38. Ishii M, Ota M, Saito S, Kinugasa Y, Akamoto S and Ito I: Lymphatic vessel invasion detected by monoclonal antibody D2-40 as a predictor of lymph node metastasis in T1 colorectal cancer. Int J Colorectal Dis 24: 1069-1074, 2009.
39. Akishima-Fukasawa Y, Ishikawa Y, Akasaka Y, Uzuki M, Inomata N, Yokoo T, Ishii R, Shimokawa R, Mukai K, Kiguchi $\mathrm{H}$, et al: Histopathological predictors of regional lymph node metastasis at the invasive front in early colorectal cancer. Histopathology 59: 470-481, 2011.

40. Kobayashi H, Higuchi T, Uetake H, Iida S, Ishikawa T, Ishiguro $M$ and Sugihara K: Resection with en bloc removal of regional lymph node after endoscopic resection for T1 colorectal cancer. Ann Surg Oncol 19: 4161-4167, 2012.

41. Kye BH, Jung JH, Kim HJ, Kang SG, Cho HM and Kim JG: Tumor budding as a risk factor of lymph node metastasis in submucosal invasive $\mathrm{T} 1$ colorectal carcinoma: A retrospective study. BMC Surg 12: 2012.

42. Nasu T, Oku Y, Takifuji K, Hotta T, Yokoyama S, Matsuda K, Tamura K, Ieda J, Yamamoto N, Takemura S, et al: Predicting lymph node metastasis in early colorectal cancer using the CITED1 expression. J Surg Res 185: 136-142, 2013.

43. Wada H, Shiozawa M, Sugano N, Morinaga S, Rino Y, Masuda M, Akaike $M$ and Miyagi Y: Lymphatic invasion identified with D2-40 immunostaining as a risk factor of nodal metastasis in T1 colorectal cancer. Int J Clin Oncol 18: 1025-1031, 2013.

44. Nishida T, Egashira Y, Akutagawa H, Fujii M, Uchiyama K, Shibayama Y and Hirose Y: Predictors of lymph node metastasis in T1 colorectal carcinoma: An immunophenotypic analysis of 265 patients. Dis Colon Rectum 57: 905-915, 2014.

45. Ryu HS, Kim WH, Ahn S, Kim DW, Kang SB, Park HJ, Park YS, Lee $\mathrm{CH}$ and Lee HS: Combined morphologic and molecular classification for predicting lymph node metastasis in early-stage colorectal adenocarcinoma. Ann Surg Oncol 21: 1809-1816, 2014.

46. Kang J, Lee HW, Kim IK, Kim NK, Sohn S-K and Lee KY: Clinical implications of microsatellite instability in T1 colorectal cancer. Yonsei Med J 56: 175-181, 2015.

47. Kawachi H, Eishi Y, Ueno H, Nemoto T, Fujimori T, Iwashita A, Ajioka Y, Ochiai A, Ishiguro S, Shimoda T, et al: A three-tier classification system based on the depth of submucosal invasion and budding/sprouting can improve the treatment strategy for T1 colorectal cancer: A retrospective multicenter study. Mod Path 28: 872-879, 2015.

48. Macias-Garcia F, Celeiro-Muñoz C, Lesquereux-Martinez L, Gude-Sampedro F, Uribarri-Gonzalez L, Abdulkader I, Alvarez-Castro A and Dominguez-Muñoz JE: A clinical model for predicting lymph node metastasis in submucosal invasive (T1) colorectal cancer. Int J Colorectal Dis 30: 761-768, 2015

49. Sohn DK, Chang HJ, Park JW, Choi DH, Han KS, Hong CW, Jung KH, Kim DY, Lim SB, Choi HS and Jeong SY: Histopathological risk factors for lymph node metastasis in submucosal invasive colorectal carcinoma of pedunculated or semipedunculated type. J Clin Pathol 60: 912-915, 2007.

50. Morodomi T, Isomoto H, Shirouzu K, Kakegawa K, Irie K and Morimatsu M: An index for estimating the probability of lymph node metastasis in rectal cancers. Lymph node metastasis and the histopathology of actively invasive regions of cancer. Cancer 63: 539-543, 1989.

51. Walgenbach-Bruenagel G, Tolba RH, Varnai AD, Bollmann M, Hirner A and Walgenbach KJ: Detection of lymphatic invasion in early stage primary colorectal cancer with the monoclonal antibody D2-40. Eur Surg Res 38: 438-444, 2006.

52. Kahn HJ and Marks A: A new monoclonal antibody, D2-40, for detection of lymphatic invasion in primary tumors. Lab Invest 82: 1255-1257, 2002

53. Kahn HJ, Bailey D and Marks A: Monoclonal antibody D2-40, a new marker of lymphatic endothelium, reacts with Kaposi's sarcoma and a subset of angiosarcomas. Mod Pathol 15: 434-440, 2002.

54. La Vecchia C and Franceschi S: Reproductive factors and colorectal cancer. Cancer Causes Control 2: 193-200, 1991.

55. Fernandez E, La Vecchia C, Balducci A, Chatenoud L, Franceschi S and Negri E: Oral contraceptives and colorectal cancer risk: A meta-analysis. Br J Cancer 84: 722-727, 2001.

56. Grodstein F, Newcomb PA and Stampfer MJ: Postmenopausal hormone therapy and the risk of colorectal cancer: A review and meta-analysis. Am J Med 106: 574-582, 1999.

57. Hendifar A, Yang D, Lenz F, Lurje G, Pohl A, Lenz C, Ning Y, Zhang $\mathrm{W}$ and Lenz HJ: Gender disparities in metastatic colorectal cancer survival. Clin Cancer Res 15: 6391-6397, 2009.

58. Newcomb PA, Zheng Y, Chia VM, Morimoto LM, Doria-Rose VP, Templeton A, Thibodeau SN and Potter JD: Estrogen plus progestin use, microsatellite instability, and the risk of colorectal cancer in women. Cancer Res 67: 7534-7539, 2007. 
59. Walter P, Green S, Greene G, Krust A, Bornert JM, Jeltsch JM, Staub A, Jensen E, Scrace G, Waterfield M, et al: Cloning of the human estrogen receptor cDNA. Proc Natl Acad Sci USA 82: 7889-7893, 1985.

60. Kuiper GG, Enmark E, Pelto-Huikko M, Nilsson S and Gustafsson JA: Cloning of a novel receptor expressed in rat prostate and ovary. Proc Natl Acad Sci USA 93: 5925-5930, 1996

61. Barone M, Scavo MP, Papagni S, Piscitelli D, Guido R, Di Lena M, Comelli MC and Di Leo A: ER $\beta$ expression in normal, adenomatous and carcinomatous tissues of patients with familial adenomatous polyposis. Scand J Gastroenterol 45: 1320-1328, 2010.

62. Konstantinopoulos PA, Kominea A, Vandoros G, Sykiotis GP Andricopoulos P, Varakis I, Sotiropoulou-Bonikou G and Papavassiliou AG: Oestrogen receptor beta (ERbeta) is abundantly expressed in normal colonic mucosa, but declines in colon adenocarcinoma paralleling the tumour's dedifferentiation. Eur J Cancer 39: 1251-1258, 2003.

63. Jassam N, Bell SM, Speirs V and Quirke P: Loss of expression of oestrogen receptor beta in colon cancer and its association with Dukes' staging. Oncol Rep 14: 17-21, 2005.
64. Nüssler NC, Reinbacher K, Shanny N, Schirmeier A, Glanemann M, Neuhaus P, Nussler AK and Kirschner M: Gender-specific differences in the expression levels of estrogen receptor subtypes in colorectal cancer. Gend Med 5: 209-217, 2008.

65. Foley EF, Jazaeri AA, Shupnik MA, Jazaeri O and Rice LW: Selective loss of estrogen receptor beta in malignant human colon. Cancer Res 60: 245-248, 2000.

66. Roger P, Sahla ME, Mäkelä S, Gustafsson JA, Baldet P and Rochefort H: Decreased expression of estrogen receptor beta protein in proliferative preinvasive mammary tumors. Cancer Res 61: 2537-2541, 2001.

67. Shaw JA, Udokang K, Mosquera JM, Chauhan H, Jones JL and Walker RA: Oestrogen receptors alpha and beta differ in normal human breast and breast carcinomas. J Pathol 198: 450-457, 2002. 